\title{
Near-surface composition and tribological behaviour of plasma nitrided titanium
}

\author{
M P Kapczinski ${ }^{1}$, E J Kinast ${ }^{2}$ and C A dos Santos ${ }^{2,3}$ \\ ${ }^{1}$ Faculdade de Odontologia-ULBRA, R. Miguel Tostes, 101, 92420-280 Canoas, RS, Brazil \\ ${ }^{2}$ Instituto de Física-UFRGS, C.P. 15051, Campus do Vale, 91501-970 Porto Alegre, RS, \\ Brazil \\ E-mail: cas@if.ufrgs.br
}

Received 21 March 2003, in final form 21 May 2003

Published 16 July 2003

Online at stacks.iop.org/JPhysD/36/1858

\begin{abstract}
Near-surface composition and tribological behaviour of plasma nitrided commercially pure (CP) Ti have been investigated using x-ray diffraction, nuclear reaction analysis, scanning electron microscopy, wear assays with stainless steel Gracey scaler and sonic apparatus, and friction coefficient measurements. The total wear behaviour can be divided into two steps. The first step is the growth of an oxynitride layer. The second step is the breakdown of the oxynitride layer during which debris is produced, increasing the friction coefficient. Each sample exhibits features that correlate with the near-surface composition. For instance, the presence of thin layers of $\varepsilon-\mathrm{Ti}_{2} \mathrm{~N}$ and $\delta$-TiN precipitating on the near-surface region control the transition from the first to the second step.
\end{abstract}

\section{Introduction}

Titanium and its alloys have been used in many biomedical applications due to several of their beneficial properties, such as low density, low modulus of elasticity, excellent corrosion resistance and biocompatibility [1-10]. However, the low wear performance of these materials in abrasive and adhesive wearing conditions has been an obstacle in their extensive use in surgical procedures. Many efforts have been made to surmount this weakness. Conventional ion implantation [2,7,11-13], plasma source nitrogen ion implantation [14], conventional nitriding [6], conventional plasma nitriding $[15,16]$, intensified plasma ion nitriding [17], PVD and CVD TiN films [18-21], powder immersion reaction assisted coating method [4], laser heating [22,23] and combined techniques [24, 25] have been reported.

Increasing interest in hardness, frictional behaviour and wear performance of surface-treated titanium and its alloys has been shown in recent literature. The underlying related principles are largely known [26], but a detailed understanding is not yet available, even at the macroscopic scale. We are specifically interested in the behaviour of contacting surfaces in relative sliding, for which the interaction between asperities plays an important role [27-29]. Recent experimental

3 Author to whom correspondence should be addressed. investigations with titanium nitride have highlighted the effects of an oxidation reaction during sliding [21]. The so-called tribo-oxidation reaction induces the growth of a surface oxynitride layer with subsequent breakdown and generation of wear particles between the contacting surfaces. The importance of a particle build-up and agglomeration on the tribological behaviour of metals has been recently highlighted based on real-time observation of the interface of sliding surfaces [30].

In this work we report x-ray diffraction (XRD), nuclear reaction analysis (NRA), scanning electron microscopy (SEM), and tribological measurements carried out on samples of commercially pure $(\mathrm{CP})$ Ti subjected to plasma nitriding at different operational conditions.

\section{Experimental details}

Samples from the same ingot of $\mathrm{CP}$ Ti were ground flat and mechanically polished to $0.25 \mu \mathrm{m}$ with diamond pastes and nitrided in conventional dc plasma nitriding equipment. Treatments were performed at different operational conditions, as summarized in table 1 . The pressure varied from $2 \times 10^{-2}$ to $5 \times 10^{-2} \mathrm{~Pa}$. Previous studies showed that the pressure effect is very small in this range [31]. Voltage in the range from 430 to $585 \mathrm{~V}$ and current from 18 to $98 \mathrm{~mA}$ were adjusted to maintain the cathode temperature between $400^{\circ} \mathrm{C}$ and $800^{\circ} \mathrm{C}$. Auxiliary 
heating was not used. The temperature was measured by a chromel-alumel thermocouple embedded in a control sample. The treatment chamber was cleaned through a four-step fillingevacuation process with nitrogen. After nitriding the samples were cooled in the treatment chamber in a pure nitrogen atmosphere. To be sure of process reproducibility, each sample was prepared in three different batches. Surface roughness measurements were made using a Talysurf 5M (Rank Taylor Hobson) profilometer.

XRD patterns were obtained in $\theta-2 \theta$ geometry (BraggBrentano goniometer) by means of a Siemens diffractometer D500 equipped with a curved graphite monochromator and $\mathrm{CoK} \alpha$ radiation and calibrated with polycrystalline $\mathrm{Si}$. Measurements were performed with a scan step of $0.05^{\circ} 2 \theta$ in the $2 \theta$ range from $20^{\circ}$ to $110^{\circ}$, with a fixed counting time of $2 \mathrm{~s}$. The profile parameters were obtained using a model-independent fitting with the program FULLPROF [32]. Starting unit cell parameters were taken from JCPDS files 44-1294 ( $\alpha$-Ti), 38-1420 $\left(\delta\right.$-TiN), 41-1352 $\left(\mathrm{TiN}_{x}\right)$ and 17-0386 $\left(\varepsilon-\mathrm{Ti}_{2} \mathrm{~N}\right)[33]$

Nitrogen depth profiles were obtained from ${ }^{14} \mathrm{~N}(\mathrm{p}, \gamma){ }^{15} \mathrm{O}$ nuclear reaction [34] using the $400 \mathrm{kV}$ ion implanter at the Institute of Physics-UFRGS with protons accelerated to $278 \mathrm{keV}$

To simulate clinical procedures, wear assays were performed with a stainless steel Gracey scaler (SS White Duflex G11-G12) and sonic apparatus (Sonicborden 2000N, Kavo, universal tip \#5). Two hundred unidirectional strokes were done with the Gracey scaler. The assays with the sonic apparatus were performed with bi-directional motion during $60 \mathrm{~s}$, under water lubrication. All the assays were manually performed by a single trained person, thereby ensuring identical, reproducible conditions.

Friction tests were accomplished with a ball-on-disk (BOD) tribometer TE79 (Plint \& Partners) using an AISI 52100 ball of $6 \mathrm{~mm}$ diameter. The experiments were done over a period of $600 \mathrm{~s}$ in air without lubrication at $\cong 23^{\circ} \mathrm{C}$ and a relative humidity between $50 \%$ and $60 \%$. A normal load of $4 \mathrm{~N}$ was applied on a rotating disk at $120 \mathrm{rpm}$.

SEM micrographs were obtained using Philips XL 20 microscope equipped with an energy-dispersive $\mathrm{X}$-ray spectrometer (EDX).

Table 1. Operational plasma nitriding conditions. Pressure $\cong 2 \times 10^{-2}-5 \times 10^{-2} \mathrm{~Pa}$.

\begin{tabular}{llll}
\hline Sample label & $\begin{array}{l}\text { Time } \\
(\mathrm{h})\end{array}$ & $\begin{array}{l}\mathrm{N}_{2} / \mathrm{H}_{2} \\
(\mathrm{vol} \%)\end{array}$ & $\begin{array}{l}\text { Temperature } \\
\left({ }^{\circ} \mathrm{C}\right)\end{array}$ \\
\hline $60403 \mathrm{~h} 400$ & 3 & $60 / 40$ & 400 \\
$60403 \mathrm{~h} 600$ & 3 & $60 / 40$ & 600 \\
$60403 \mathrm{~h} 800$ & 3 & $60 / 40$ & 800 \\
$80203 \mathrm{~h} 400$ & 3 & $80 / 20$ & 400 \\
$80203 \mathrm{~h} 600$ & 3 & $80 / 20$ & 600 \\
$80203 \mathrm{~h} 800$ & 3 & $80 / 20$ & 800 \\
$80206 \mathrm{~h} 600$ & 6 & $80 / 20$ & 600 \\
$20803 \mathrm{~h} 400$ & 3 & $20 / 80$ & 400 \\
$20803 \mathrm{~h} 600$ & 3 & $20 / 80$ & 600 \\
$20803 \mathrm{~h} 800$ & 3 & $20 / 80$ & 800 \\
$20806 \mathrm{~h} 800$ & 6 & $20 / 80$ & 800 \\
$20809 \mathrm{~h} 400$ & 9 & $20 / 80$ & 400 \\
$20809 \mathrm{~h} 600$ & 9 & $20 / 80$ & 600 \\
\hline
\end{tabular}

\section{Results and discussion}

All the samples were submitted to assays with the sonic apparatus. Except for samples $20 \% \mathrm{~N}_{2}-80 \% \mathrm{H}_{2}-3 \mathrm{~h}-800^{\circ} \mathrm{C}$ (20803h800) and $80 \% \mathrm{~N}_{2}-20 \% \mathrm{H}_{2}-3 \mathrm{~h}-600^{\circ} \mathrm{C}(80203 \mathrm{~h} 600)$, all the others, including the $\mathrm{CP} \mathrm{Ti}$ one, showed severe damage after the test. Although both samples had good tribological performances, sample $20803 \mathrm{~h} 800$ exhibited a golden colour and, from an aesthetic point of view, it is not appropriate for dental prosthetics. Hence, only sample $80203 \mathrm{~h} 600$ is potentially useful for clinical use. The correlation between operational parameters and tribological performance is expected to be mediated by the near-surface physical-chemical state, including chemical composition and crystallography.

Tests on CP Ti with sonic apparatus produced an effect similar to those observed after tests with the Implacare scaler [35] and Cavitron [35,36]. Roughening of the surface and material loss are evident. A weak macroscopic damage was observed in sample 20803h800, which is evidenced by small linear scratches and abrasions along the assay direction. On the contrary, no macroscopic damage was observed on sample $80203 \mathrm{~h} 600$, but only a subtle change in brightness, which could have been due to surface depressions. Similar effects were observed after tests with the Gracey scaler. While the $\mathrm{CP}$ Ti sample appeared to be severely damaged, as indicated by patches and abrasions in figure 1( $a$ ), samples $20803 \mathrm{~h} 800$ and
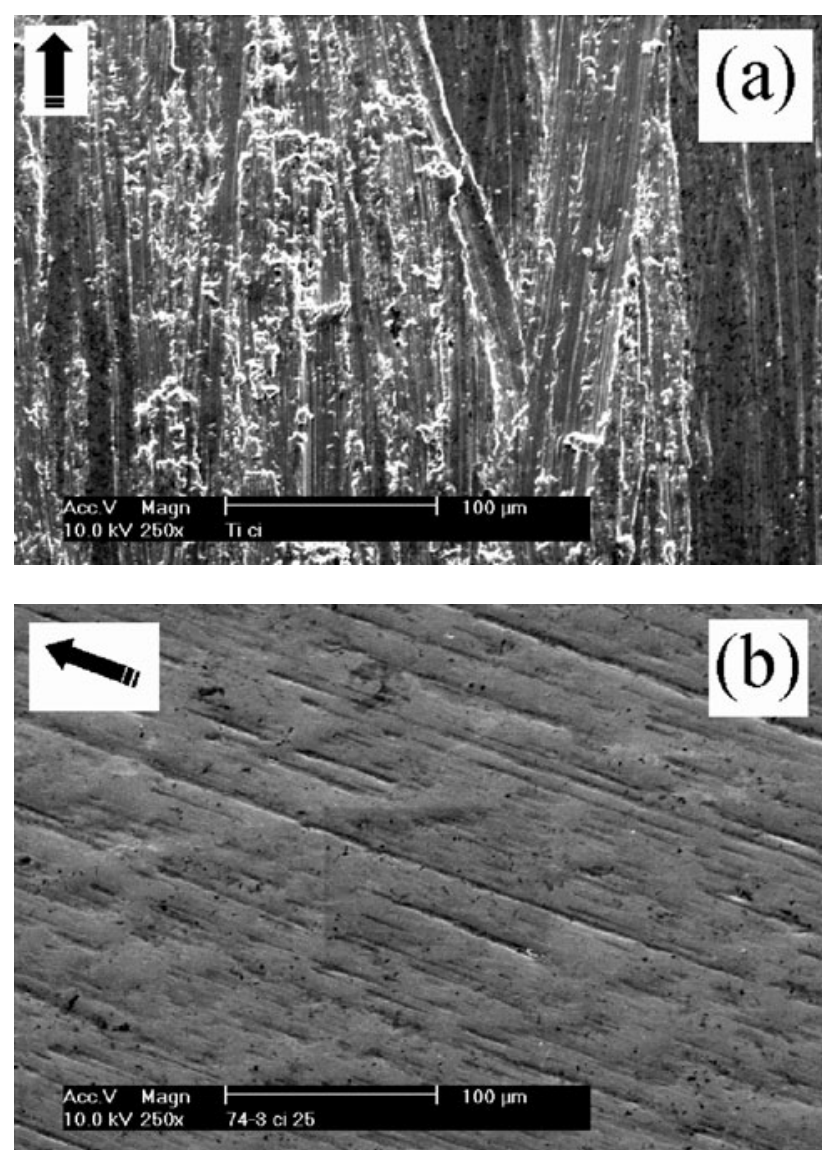

Figure 1. SEM photomicrographs after test with Gracey scaler in: (a) CP Ti; (b) sample 80203h600. The arrows indicate the direction of the assays. 

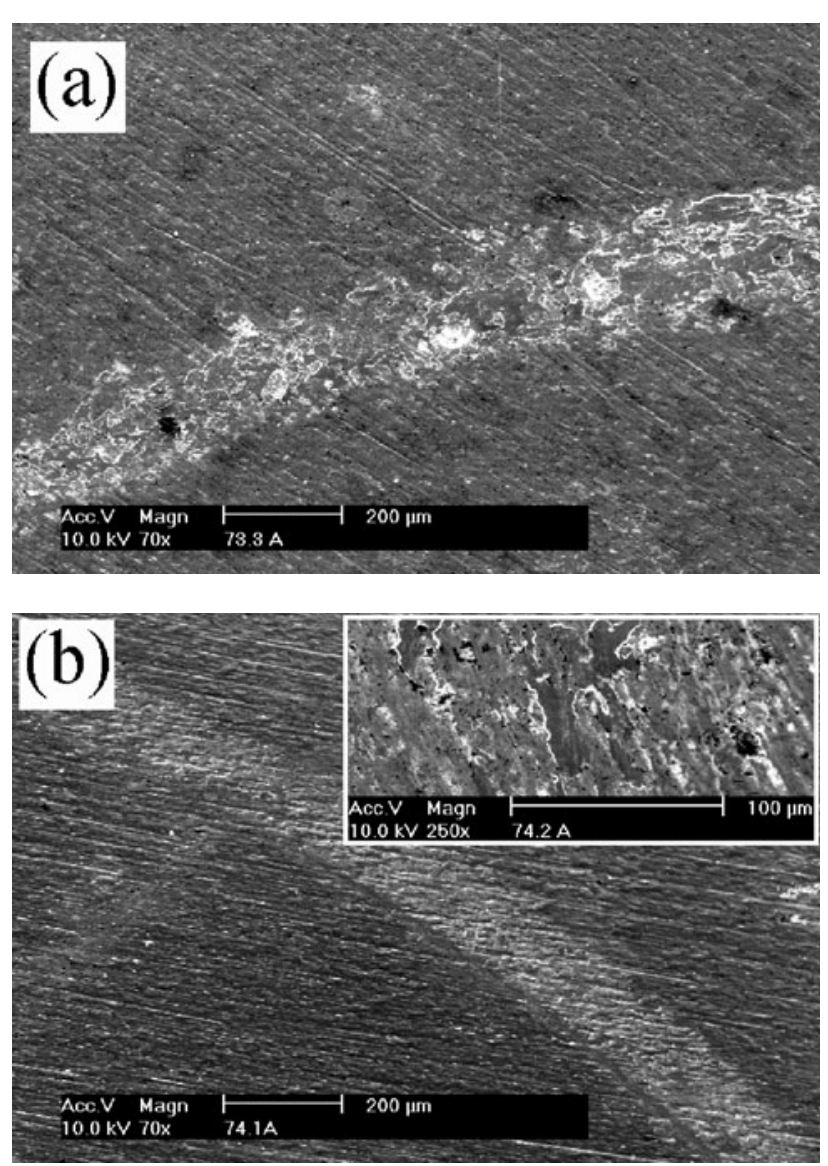

Figure 2. SEM photomicrographs after BOD assays with: (a) sample 20803h800; (b) sample 80203h600. The inset shows adhered material on sample $80203 \mathrm{~h} 600$.

$80203 \mathrm{~h} 600$ remain practically intact after this assay, as can be seen in figure $1(b)$ for the sample 20803h800.

The BOD test for CP Ti showed a wear track of about $0.7 \mathrm{~mm}$, with many grooves, typical of abrasive wear. For sample $20803 \mathrm{~h} 800$ (figure $2(a)$ ) the wear track was about $0.2 \mathrm{~mm}$ and no continuous grooves were observed. However, discontinuous scratches and material loss are evident. For sample 80203h600, the ball track showed a brightness that can be attributed to a surface dent. No sign of scratches was observed on this sample (see figure 2(b)). Nevertheless, as shown in the inset of the figure 2(b), adhered material was observed in a photomicrography obtained with $250 \times$ magnification. Energy-dispersive x-ray spectrometry performed on these wear particles showed the presence of iron and oxygen, suggesting that they were from the steel ball.

The coefficient of friction $(\mu)$ as a function of the sliding time for samples CP Ti, $20803 \mathrm{~h} 800$ and $80203 \mathrm{~h} 600$ are shown in figure 3. The features are typical. After an initial period of about $200 \mathrm{~s}$ (400 revolutions) for CP $\mathrm{Ti}$ and $20803 \mathrm{~h} 800$ samples, and about $400 \mathrm{~s}$ for $80203 \mathrm{~h} 600$ sample the coefficient of friction increases from $\cong 0.30$ to $\cong 0.45$ for the control sample, from $\cong 0.10$ to $\cong 0.50$ for sample $20803 \mathrm{~h} 800$ and from $\cong 0.05$ to $\cong 0.40$ for sample $80203 \mathrm{~h} 600$. The evolution of the coefficient of friction can be attributed to two causes that operate in a synergistic way. On the one hand, the eroding of the protective layer leaves the surface more weak to wear. On

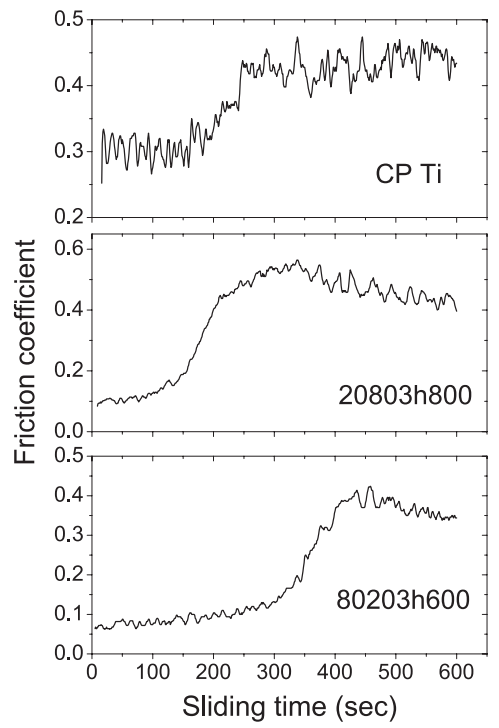

Figure 3. Friction coefficient as a function of the sliding time for indicated samples.

Table 2. Surface roughness measurements for CP Ti and $80203 \mathrm{~h} 600$ samples. $R_{\mathrm{a}}$ is the mean arithmetic deviation from the median line of the surface profile.

\begin{tabular}{lll}
\hline Sample & Wear test & $R_{\mathrm{a}}(\mu \mathrm{m})$ \\
\hline CP Ti & No & 0.076 \\
$80203 \mathrm{~h} 600$ & No & 0.134 \\
CP Ti & Sonic apparatus & 0.122 \\
$80203 \mathrm{~h} 600$ & Sonic apparatus & 0.141 \\
CP Ti & Gracey scaler & 0.143 \\
$80203 \mathrm{~h} 600$ & Gracey scaler & 0.098 \\
\hline
\end{tabular}

the other hand, the debris so produced increases the coefficient of friction.

The surface roughness measurements performed on $\mathrm{CP}$ $\mathrm{Ti}$ and $80203 \mathrm{~h} 600$ samples are summarized in table 2. It is interesting to observe that the roughness parameter for the nitrided sample $\left(R_{\mathrm{a}}=0.134\right)$ is higher than that of CP Ti ( $\left.R_{\mathrm{a}}=0.076\right)$. A similar increase on $R_{\mathrm{a}}$ had been reported earlier for CP Ti submitted to intensified plasma ion nitriding [37]. However, the $R_{\mathrm{a}}$ value for CP Ti increases considerably (more than 60\%) after both assays (Sonic apparatus and Gracey scaler), while for the nitrided sample submitted to the Sonic apparatus, the increase in the $R_{\mathrm{a}}$ value is about $5 \%$. And, more astonishingly, it decreases after the test with the Gracey scaler (about 27\%). As will be discussed later, this decrease can be attributed to the smearing of the oxynitride layer on the surface during the wear test [13].

To determine the physico-chemical state of the sliding surfaces, XRD and NR measurements were carried out. Typical XRD patterns are displayed in figure 4. Crystal parameters obtained from Rietveld refinement, as illustrated in figure 5 for sample $80203 \mathrm{~h} 600$, are summarized in table 3 . As can be seen in table 4, samples 80203 h600 and 20803h800 are the only samples not containing $\mathrm{TiO}_{2}$ in amounts detectable by XRD. All the samples containing this oxide in an appreciable amount exhibit low wear resistance. On the other hand, for good performance against wear, the presence of some kind of titanium nitride is necessary. In a conventional plasma 

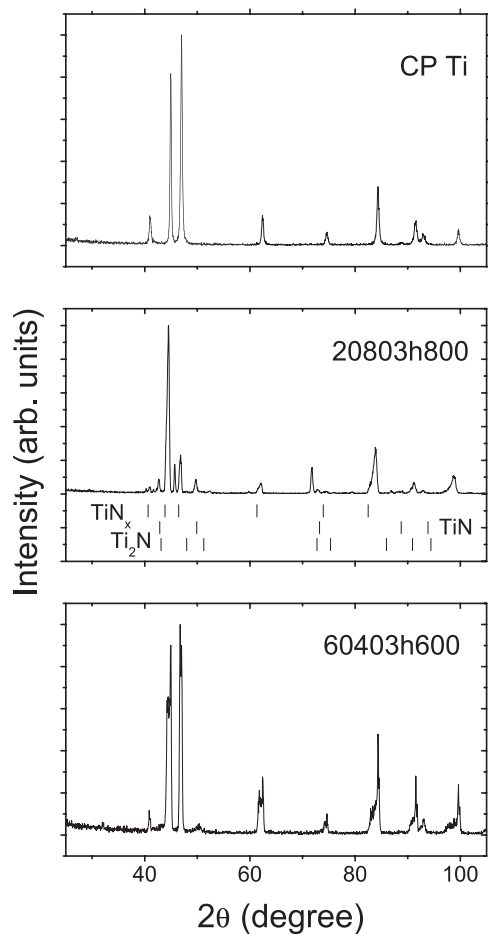

Figure 4. Representative parts of the XRD patterns for $\mathrm{CP}$ Ti and samples nitrided at indicated experimental conditions (atmosphere-time-temperature).

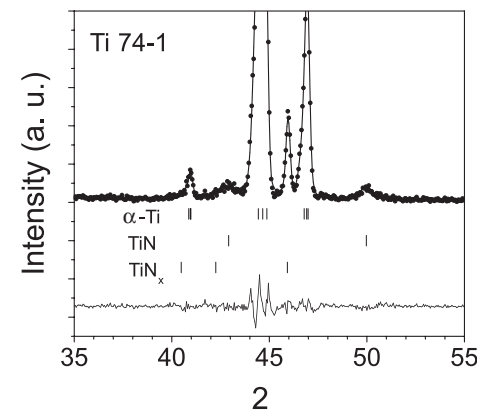

Figure 5. Rietveld analysis for sample $80203 \mathrm{~h} 600$. Dots represent observed data. The solid line represents the calculated pattern. The line at the bottom is a plot of the residual spectrum, i.e. observed minus calculated intensities. Ti, TiN and $\mathrm{TiN}_{x}$ reflections are indicated by vertical bars.

nitriding equipment, titanium nitride and oxide growth are typically dependent on plasma atmosphere, temperature and treatment time. With respect to our operational conditions, nitriding at $400^{\circ} \mathrm{C}$ does not produce nitride or oxide for any plasma atmosphere used in this work, even for treatment as long as $9 \mathrm{~h}$. Therefore, all the samples nitrided at this temperature behave like $\mathrm{CP}$ Ti. For higher temperatures, the effect of the plasma atmosphere is noticed because of its reduction capacity. For instance, nitriding during $3 \mathrm{~h}$ at $800^{\circ} \mathrm{C}$ produced $\mathrm{TiO}$ and $\mathrm{TiO}_{2}$ in samples treated in $60 / 40$ and $80 / 20$ atmospheres, but not in samples treated in a 20/80 atmosphere (see table 4 and figure 4).

For samples $20803 \mathrm{~h} 800$ and $80203 \mathrm{~h} 600$, the main contribution to the XRD pattern is due to $\alpha$-Ti, whereas the minor ones are due to $\mathrm{TiN}, \mathrm{TiN}_{x}$ and $\mathrm{Ti}_{2} \mathrm{~N}$. The hexagonal phase $\alpha$-Ti was refined with three different cell-parameter values, which we name $\alpha-\operatorname{Ti}(1), \alpha-\operatorname{Ti}(2)$ and $\alpha$-Ti(3). In fact, these phases can be attributed to $\mathrm{N}$-saturated $\alpha$-phase or to substoichiometric $\alpha-\mathrm{TiN}_{x}$, with different nitrogen concentrations. For example, $\alpha-\mathrm{TiN}_{0.25}$ [12], $\alpha-\mathrm{TiN}_{0.26}$ [JCPDS file 44-1095] and $\alpha-\mathrm{TiN}_{0.30}$ [JCPDS file 41-1352] have been reported with cell-unit parameters quite close to those displayed in table 3 . The N-concentration profile obtained with NRA for sample $80203 \mathrm{~h} 600$ is shown in figure 6 . From about 50 to $300 \mathrm{~nm}$ the concentration increases to $25 \%$. Between 300 and $450 \mathrm{~nm}$ the concentration decreases almost linearly from about $25 \%$ to $15 \%$. Taking into account early results $[13,37,38]$, we expect a thin layer containing $\varepsilon-\mathrm{Ti}_{2} \mathrm{~N}$ between 300 and $450 \mathrm{~nm}$. The lack of reflection attributed to this nitride in the XRD pattern for this sample is probably because its layer thickness is below the detection limit for $\mathrm{CoK} \alpha$ radiation.

We can now discuss the correlation between near-surface composition and tribological behaviour, mainly for sample 80203h600. During the first step of the sliding experiment (up to $\cong 350 \mathrm{~s}$ ), surface oxidation is promoted by the increase of temperature in the contact zone. As $\alpha-\mathrm{TiN}_{x}$ reacts strongly with oxygen [13], an oxynitride layer quickly grows with the sliding time, resulting in a low friction coefficient. When this layer reaches a critical thickness it peels off, producing debris and increasing the friction coefficient. At this stage, the sample $80203 \mathrm{~h} 600$ behaves slightly differently as compared to sample 20803h800. For the former, whose main component of the near-surface layer is $\alpha-\mathrm{TiN}_{x}$, the debris so generated smeared and transformed into an amorphous layer, which provides a low friction coefficient [39]. On the contrary, for sample 20803h800, the near-surface composition includes $\varepsilon-\mathrm{Ti}_{2} \mathrm{~N}$ and $\delta$-TiN precipitates. As is known [13], these nitrides are very hard and wear particles pulled off at the surface asperities act as an abrasive. The near-surface inhomogeneity, produced by the $\alpha-\mathrm{TiN}_{x}+\varepsilon-\mathrm{Ti}_{2} \mathrm{~N}+\delta$-TiN mixture, induces surface breaking at a sliding time $(\cong 150 \mathrm{~s})$ lesser than that of sample $80203 \mathrm{~h} 600(\cong 350 \mathrm{~s})$. Besides, $\varepsilon-\mathrm{Ti}_{2} \mathrm{~N}$ and $\delta$-TiN particles within the debris increase the friction coefficient to about 0.6 (see figure 3).

\section{Summary and conclusions}

Near-surface composition and tribological behaviour of plasma nitrided $\mathrm{CP}$ Ti have been investigated using XRD, NRA, SEM, wear assays with a stainless steel Gracey scaler and sonic apparatus, and friction coefficient measurements. More than 40 samples were prepared with different nitriding conditions. Based on the tribo-oxidative wear process, the total behaviour can be divided into two steps. The first step is the growth of an oxynitride layer $\alpha-\operatorname{Ti}(\mathrm{N}, \mathrm{O})_{x}$, which exhibits low friction coefficient. During the second step, breakdown of the oxynitride layer produces debris and increases the friction coefficient. Each sample exhibited features correlated with the near-surface composition. For instance, the second step starts earlier for sample $20803 \mathrm{~h} 800$ than for sample $80203 \mathrm{~h} 600$, probably due to the presence of an appreciable amount of $\varepsilon-\mathrm{Ti}_{2} \mathrm{~N}$ and $\delta$-TiN precipitates on the near-surface region. Also probably related to the presence of these precipitates is the higher friction coefficient in the second step of the sample $20803 \mathrm{~h} 800$ as compared to that observed for sample 80203 h600. 
Table 3. Cell-unit parameters obtained for indicated samples. Numbers in brackets designate $\pm 1 \sigma$ on the last decimal given. $R_{\mathrm{B}}$ is the Bragg $R$-factor, given by $R_{\mathrm{B}}=100\left(\sum\left|I_{\mathrm{obs}}-I_{\text {calc }}\right| / \sum I_{\mathrm{obs}}\right)$.

\begin{tabular}{llllll}
\hline Sample & Phase & Space group & $a(\AA)$ & $c(\AA)$ & $R_{\mathrm{B}}$ \\
\hline CP Ti & $\alpha-\mathrm{Ti}$ & $\mathrm{P6}_{3} / \mathrm{mmc}$ & $2.9513(4)$ & $4.6832(7)$ & 1.80 \\
$80203 \mathrm{~h} 600$ & $\alpha-\mathrm{Ti}(1)$ & $\mathrm{P}_{3} / \mathrm{mmc}$ & $2.959(8)$ & $4.731(7)$ & 1.16 \\
& $\alpha-\mathrm{Ti}(2)$ & $\mathrm{P6}_{3} / \mathrm{mmc}$ & $2.950(7)$ & $4.687(8)$ & 2.46 \\
& $\alpha-\mathrm{Ti}(3)$ & $\mathrm{P6}_{3} / \mathrm{mmc}$ & $2.953(3)$ & $4.709(1)$ & 1.04 \\
& $\alpha-\mathrm{TiN}{ }_{x}$ & $\mathrm{P6}_{3} / \mathrm{mmc}$ & $2.984(0)$ & $4.95(7)$ & 3.30 \\
& $\delta$-TiN & $\mathrm{Fm} 3 \mathrm{~m}$ & $4.24(4)$ & $4.24(4)$ & 4.06 \\
\hline
\end{tabular}

Table 4. Phases detected from XRD measurements.

\begin{tabular}{|c|c|c|c|c|c|c|c|c|}
\hline Sample label & $\alpha-\operatorname{Ti}(1)$ & $\alpha-\operatorname{Ti}(2)$ & $\alpha-\operatorname{Ti}(3)$ & $\alpha-\operatorname{TiN}_{x}$ & $\delta-\mathrm{TiN}$ & $\varepsilon-\mathrm{Ti}_{2} \mathrm{~N}$ & $\mathrm{TiO}$ & $\mathrm{TiO}_{2}$ \\
\hline $60403 \mathrm{~h} 400$ & & & & & & & & \\
\hline $60403 \mathrm{~h} 600$ & & & & & & & & \\
\hline $60403 \mathrm{~h} 800$ & & & & & & & & \\
\hline $80203 \mathrm{~h} 400$ & & & & & & & & \\
\hline 80203 h600 & & & & & & & & \\
\hline $80203 \mathrm{~h} 800$ & & & & & & & & \\
\hline $80206 h 600$ & & & & & & & & \\
\hline $20803 \mathrm{~h} 400$ & & & & & & & & \\
\hline 20803h600 & & & & & & & & \\
\hline $20803 \mathrm{~h} 800$ & & & & & & & & \\
\hline 20806h800 & & & & & & & & \\
\hline 20809h400 & & & & & & & & \\
\hline 20809h600 & & & & & & & & \\
\hline
\end{tabular}

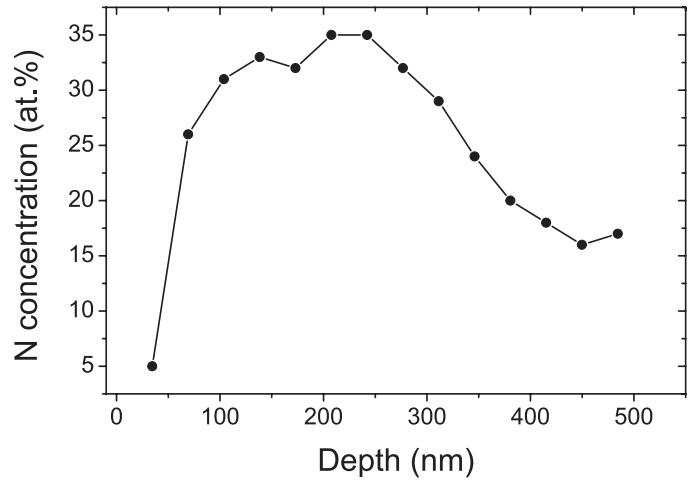

Figure 6. Nitrogen profile for sample 80203h600, obtained with NRA.

\section{Acknowledgments}

This work was supported in part by the Brazilian agencies CAPES (PROCAD), CNPq(PRONEX) and FAPERGS.

\section{References}

[1] Filip P, Lausmaa J, Musialek J and Mazanec K 2001 Biomaterials 222131

[2] Krupa D, Basrzkiewicz J, Kozubowski J A, Barcz A, Sobczak I W, Bilinski A, Lewandowska-Szumiel M and Rajchel B 2001 Biomaterials 222139

[3] Es-Souni M, Es-Souni M and Brandies H F 2000 Biomaterials 222153

[4] Shenhar A, Gotman I, Radin S, Ducheyne P and Gutmanas E Y 2000 Surf. Coat. Technol. 126210

[5] Raimondi M T and Pietrabissa R 2000 Biomaterials 21907

[6] Venugopalan R, George M A, Weimer J J and Lucas L C 1990 Biomaterials 201709
[7] Dong H, Shi W and Bell T 1999 Wear 225-229 146

[8] Raikar G N, Gregory J C, Ong J L, Lucas L C, Lemons J E, Kaeahara D and Nakamura M 1995 J. Vac. Sci. Technol. A 132633

[9] Lloyd C H et al 1995 J. Dent. 2367

[10] Mezger P R and Creugers N H J 1992 J. Dent. 20342

[11] Itoh Y, Itoh A, Azuma H and Hioki T 1999 Surf. Coat. Technol. 111172

[12] Guemmaz M, Mosser A and Grob J J 1997 Appl. Phys. A 64407

[13] Pons F, Pivin J C and Farges G 1987 J. Mater. Res. 2580

[14] Qiu X, Conrad J R, Dodd R A and Worzala F J 1990 Metall. Trans. 211663

[15] Wierzchon T and Fleszar A 1997 Surf. Coat. Technol. 96205

[16] Salehi M, Bell T and Morton P H 1992 J. Phys. D: Appl. Phys. 25889

[17] Meletis E I 2002 Surf. Coat. Technol. 14995

[18] Shima M, Okado J, McColl I R, Waterhouse R B, Hasegawa T and Kasaya M 1999 Wear 225-229 38

[19] Wu P Q, Drees D, Stals L and Celis J P 1999 Surf. Coat. Technol. 113251

[20] Vitchev R G, Blanpain B and Celis J P 1999 Wear 231220

[21] Vancoille E, Banpain B, Xingpu Y, Celis J P and Roos J R 1994 J. Mater. Res. 9992

[22] Yilbas B S and Shuja S Z 2000 Surf. Eng. 16519

[23] L'Enfant H, Laurens P, Sainte Catherine M C, Dubois T and Amouroux J 1997 Surf. Coat. Technol. 96169

[24] Labudovic M, Kovacevic R, Kmecko I, Chan T I, Blecic D and Blecic Z 1999 Metall. Mater. Trans. A 301597

[25] Rodrigo M T, Jiménez C, Vázquez L, Alonso F, Fernández M and Martínez-Duart J M 1998 J. Mater. Res. 132117

[26] Holmberg K and Matthews A 1989 Coatings Tribology: Properties, Techniques and Applications in Surface Engineering (Amsterdam: Elsevier) p 33

[27] Yang Y, Torrance A A and Oxley P L B 1996 J. Phys. D: Appl. Phys. 29600

[28] Ford I J 1993 J. Phys. D: Appl. Phys. 262219

[29] Ogilvy J A 1992 J. Phys. D: Appl. Phys. 251798

[30] Hwang D H, Kim D E and Lee S J 1999 Wear 225-229 427 
[31] da Silva S L R, Kerber L O, Amaral L and dos Santos C A 1999 Surf. Coat. Technol. 116-119 342

[32] Rodriguez-Carvajal J 1993 Physica B 19255

[33] Joint Committee on Powder Diffraction Standards 1995 (Swarthmore, Pennsylvania, USA: International Centre for Diffraction Data)

[34] Feldman L C and Picraux S T 1977 Ion Beam Handbook for Material Analysis ed M Mayer and E Rimini (London: Academic) p 109
[35] Brookshire F V G, Nagy W W, Dhuru V R, Ziebert G J and Chada S 1997 J. Prostet. Dent. 78286

[36] Rapley J W, Swan R H, Halmon W W and Mills M P 1990 Int. J. Oral. Maxillofac. Implants 547

[37] Muraleedharan T M and Meletis E I 1992 Thin Solid Films 221104

[38] Badini C, Gianoglio C, Bacci T and Tesi B 1988 J. Less-Common Met. 143129

[39] de Wit E, Froyen L and Celis J P 1998 Wear 221124 